\title{
URSAMAIOR, DE MÁRIO CLÁUDIO: SETE ESTRELAS, UM CORPO CADENTE
}

\author{
URSAMAIOR, BY MARIO CLAUDIO: \\ SEVEN STARS, A FALLING BODY
}

Mariana Caser da Costa ${ }^{1}$

\section{RESUMO}

No ano 2000, o escritor português Mário Cláudio lança Ursamaior, romance que não escapa à tendência do autor de ficcionalizar dados do real. $\mathrm{O}$ livro, juntamente com Oríon (2003) e Gémeos (2004), compõe o que Maria Theresa Abelha Alves denomina a "Trilogia das Constelações". O primeiro elemento desse tríptico romanesco expõe diversas formas de violência, entre as quais uma desgastante cena de estupro sofrida por Jorge, última estrela a compor a constelação de Ursamaior. Partiremos, portanto, dessa cena, de modo a refletir sobre o papel preponderante do lúdico sobre o corpo enlutado, aos moldes do que propõe, por exemplo, Walter Benjamin, na Origem do drama barroco alemão. Igualmente, procuraremos enfatizar o jogo intersemiótico que estabelece diálogo entre a literatura e outras linguagens artísticas, neste romance, notadamente, o cinema. Por fim, a escrita será entendida como forma de sutura de almas e corpos dilacerados, ou ainda como forma de reorganização do caos, destacando-se o caráter neobarroco do par luto-jogo, além da autorreflexão e da metalinguagem como estratégias textuais não raro evidenciadas pelas obras marioclaudianas.

PALAVRAS-CHAVE: Mário Cláudio; violência física; sublimação pela arte.

\section{ABSTRACT}

In the year 2000, Portuguese writer Mario Claudio publishes Ursamaior, a novel that do not escape from his tendency of turning real data into fictional pieces. Together with Orion (2003), and Gemeos (2004), that book composes the "Trilogy of the Constellations", according to Maria Theresa Abelha Alves. The first element of that triptych exposes several types of 
violence, among which an exhausting rape scene suffered by Jorge, the last star of Ursamaior constellation. Therefore, we will depart from that scene in order to reflect on the preponderant role of the playful element over the mourning body, basing our text on, for example, Walter Benjamin's Origin of the German Baroque Drama. We will also focus on the intersemiotic game that establishes a dialogue between literature and other artistic languages, in this novel, notably cinema. Finally, the act of writing will be understood as a means of suturing torn souls and bodies, and also as a way of reorganizing chaos, highlighting the neobaroque characteristic of the pair mourning-game, and the self-reflection and the metalanguage as textual strategies not rarely evidenciated by mauroclaudian works.

KEYWORDS: Mario Claudio; physical violence; sublimation by writing.

O único fim da literatura é tornar os leitores capazes de melhor gozar a vida, ou de melhor suportá-la (JOHN-

SON, Samuel. In: COMPAGNON, 2009, p. 48).

No ano 2000, o escritor português Mário Cláudio, reconhecido pela publicação de biografias ficcionalizadas e por um constante diálogo entre a sua produção e a de outros artistas e outras obras de arte, oriundas de diferentes linguagens, lança Ursamaior, primeiro livro de uma trilogia composta, ainda, por Oríon (2003) e Gémeos (2004). Não em vão os livros recebem nomes de constelações: é para o céu que o escritor se volta ao criar as personagens que constituem esses romances, refletindo, em suas existências cautelosamente tecidas, a mitologia por trás dos conjuntos estelares.

Sabe-se que a constelação de Oríon está relacionada à história dos judeus, e, portanto, é do degredo em África, a mando de D. João II, a que sete crianças judias são destinadas, que o romance homônimo trata. A constelação de Gêmeos é explicada pelo mito da rivalidade entre os irmãos Castor e Pólux, nomes das duas principais estrelas desse conjunto, e que, em Gémeos, são ressignificadas nas personagens de D. Francisco - o pintor espanhol Goya - e Rosarito - a filha de sua companheira, Dona Leocadia -, que mantêm entre si uma tensa e estreitíssima relação, de que emerge a cobiça pela sabedoria de um e pela juventude da outra. Por fim, a constelação de Ursa Maior, relacionada, pelos árabes, à morte, explica-se, pela cultura grega, com o mito de Calisto:

Segundo a mitologia grega, Zeus apaixonou-se por Calisto, a bela ninfa dos bosques e companheira de Ártemis. Zeus ficou de tal modo fascinado pela sua beleza que, para se aproximar dela, tomou as feições de Ártemis. Calisto acolheu Zeus sem desconfiança, mas quando reconheceu o seu erro já era tarde demais, e concebeu dele um filho, que se chamou 
Arcas. Hera, esposa de Zeus, ficou furiosa e castigou Calisto, transformando-a numa ursa. Um dia, a irreconhecível Calisto e Arcas encontraram-se. Calisto abriu os braços para acolher o filho, mas este, julgando-se atacado pela gigantesca ursa, preparou-se para matá-la. À última da hora, Zeus evitou a tragédia e transformou Arcas num pequeno urso, arrastando ambos para os céus. Hera, contudo, empurrou os dois para perto do polo norte, onde as estrelas são sempre visíveis - mãe e filho nunca teriam descanso. Arcturo, a brilhante estrela do Boieiro, ficou de guarda às ursas para que não se afastassem do gélido polo (URSA MAIOR, 20--).

Engano, traição, castigo e reclusão são os elementos que movem os enredos dos três romances, mas, sobretudo, o de Ursamaior, em que corpos privados de liberdade lançam mão de recursos lúdicos para tecer estrelas, ou seja, para, retomando o excerto que nos serve como epígrafe, "melhor gozar a vida" ou "melhor suportá-la". É sobre esse romance que nos debruçaremos neste exercício de leitura.

Contando histórias distintas, a trilogia, conforme mencionado, trata de situações de aprisionamento, seja no degredo, seja na velhice, mas é em Ursamaior que a prisão toma contornos literais. O crime real, cometido por um estudante do Instituto de Medicina Abel Salazar, na Universidade do Porto, em 1994, torna-se ficção sob a pena de Mário Cláudio, que afirma ter entrevistado, na cadeia, aquele que no romance chama-se Henrique e dá vida ao autor de tal crime, além de outros reclusos, que o teriam inspirado na composição das demais personagens.

A estrutura de Ursamaior assemelha-se à de um jogo cujas peças são movidas alternadamente: Henrique, o estudante de Medicina, exerce papel principal, visto que suas partes narrativas surgem intercaladas com as das outras seis personagens, figurando nos capítulos ímpares do romance, que totaliza 12 subdivisões. Nos intervalos pares das partes referentes a Henrique estão as demais estrelas da constelação, seus "camaradas de cadeia", conforme lemos no verso da edição do livro: "Gerardo, o jogador, Sérgio, o violador, Rogério, o burlão, Cristiana, o transformista, Albino, o traficante de antiguidades, Jorge, o cumpridor de um destino inconfessável". Ao longo da leitura, cada personagem é apresentada em duas partes: primeiramente, um narrador-observador não identificado conta o tempo presente do crime cometido, e, em seguida, ganha voz a respectiva personagem, que expõe trechos reveladores de suas impressões sobre momentos anteriores e contemporâneos ao do aprisionamento ${ }^{2}$.

Destacamos aqui a narrativa de Jorge, que protagoniza as últimas cenas do romance. Nelas, o leitor é apresentado ao rapaz pobre, órfão de pai, envolvido com companhias abastadas com quem passa a conduzir a vida de maneira desregrada, fútil e irresponsável. Viciado em Rohypnol, comprimidos que lhe causam efeito alucinógeno, ele participa do malsucedido assalto a um "agente da judiciária" (CLÁUDIO, 2000, p. 164) e, por 
isso, é preso, tendo por companhias de cela "o amulatado que se enfurece, quando alguém se lhe encosta ao colchão, o louro que não para de vomitar, um que nunca fala, um que de noite soluça, mais um que não pronuncia palavra que não anteceda desta fórmula, 'Ora vamos lá conversar'” (CLÁUDIO, 2000, p. 168).

Após a narração do delito, o próprio Jorge conta a história de sua vida, e essa alternância de vozes altera, aos poucos, a empatia do leitor: se, antes, a figura do delinquente irresponsável era o objeto narrado, na segunda parte Jorge apresenta sua história em primeira pessoa, num tom melancólico que em muito difere da objetividade do registro quase policial que marca a primeira parte do capítulo destinado a ele. Agora, o leitor reconhece em Jorge o homem que, por vontade própria, encontra-se em tratamento médico e psicológico para amenizar os traumas causados pelo estupro que sofrera na prisão.

A narrativa, além de trazer referências ao cinema da década de 1990, como, por exemplo, ao insistir numa suposta semelhança entre Jorge e a beleza delicada de Leonardo DiCaprio, atestada pela confirmação de amigos estrangeiros ("A irmã do meu amigo transformara-se muito entretanto desde que uma alemã lhe jurara que eu era igual ao Leonardo DiCaprio" [CLÁUDIO, 2000, p. 172]), constantemente imprime ao texto técnicas comuns à linguagem cinematográfica, em que o corpo da personagem, descrito em movimentos mais ou menos velozes, confere o tom exato à narrativa. Por exemplo, a acelerada cena do assalto vai perdendo velocidade, com a ajuda da pontuação e de uma eficaz seleção vocabular, à medida que o efeito da droga e a adrenalina decorrente da ação diminuem - "E um entorpecimento apossa-se dos transgressores. O calor diminuiu, a aragem abateu, o cansaço estende-se por cima das coisas como uma teia incorruptível" (CLÁUDIO, 2000, p. 164).

Podemos relacionar ainda a dicção de uma linguagem aproximada do cinema nesta obra com a sequência da entrada de Jorge na prisão. Após a descrição dessa cena, o rapaz "encosta-se à parede, deixa-se escorregar vagarosamente para o chão, permanece ali amochado, vencido por um adormecimento afável, desses que entregam a chave de todos os mistérios, e aliviam a ardência de todas as feridas" (CLÁUDIO, 2000, p. 165-166), numa encenação de dor e solidão já consagrada pela dramaturgia - pensemos, por exemplo, nas tantas cenas em que personagens reproduzem esse gesto de profundo lamento e exagerado teor dramático, seja em novelas, filmes ou seriados, sempre embaladas por uma trilha sonora igualmente triste.

Após o choque inicial, numa tomada reversa, a cena de entrada é como que rebobinada pela pena do escritor:

O rapaz empreende o percurso inverso ao itinerário inaugural, e fecha-se-lhe na retaguarda uma porta metálica, abre-se-lhe o corredor diante dos passos, rangem os gonzos de uma grade, desanda uma chave no ferrolho, escancara-se um portão para que ele saia (CLÁUDIO, 2000, p. 167). 
A trajetória exatamente oposta à da entrada na prisão acontece após nova ingestão de um comprimido de Rohypnol, desta vez oferecido por um dos presos. Esse movimento de fuga parece fundar a narrativa de Jorge, que foge de sua origem humilde, da família que precariamente formou e do trabalho como pizzaiolo, sempre fazendo uso da droga, que, apesar de o libertar da crueza de sua realidade, leva-o, em mente e corpo, à ruína. Vale ressaltar que o texto relativo a Jorge é ambientado em um espaço repleto de referências à contemporaneidade e a um forte apelo midiático e pop, além de nele haver uma supervalorização do estrangeiro, em especial a influência estadunidense e da Europa além de Portugal, que também (des) orientam a existência da personagem. Todos esses fatores, apossando-se de Jorge, de forma metafórica antecipam a violação física que ele virá a sofrer.

Além disso, os elementos componentes do cenário em que Jorge é ambientado, dentro ou fora da cadeia, remetem ao kitsch e ao exagero como, por exemplo, no início do capítulo, quando "brilham-lhe nos olhos as montras e os anúncios, berra o tema que foi o último sucesso dos Agonizing Terror, não quer saber de coisa alguma excepto do estonteamento incontrolável que o invade" (CLÁUDIO, 2000, p. 161), ou na invocação à mãe, à casa e à infância através da recorrente lembrança de uma "colcha com o desenho de dois tigres, a lutar na floresta" (CLÁUDIO, 2000, p. 161) -, contribuindo para a sensação de sufocamento que culminará com o estupro do corpo do rapaz. Passemos à cena propriamente dita para, em seguida, tecermos algumas considerações sobre seus desdobramentos no romance. Conta-nos Jorge:

Encolhia-me no beliche com cagaço de que alguém se esticasse ali ao lado, entretinha-me a contar os astros do céu que não conseguia avistar. E daquela maré, tinha eu já adormecido, sonhava que o foguetão ia descolar comigo lá dentro, uma compressão do camandro, eu a sufocar, a sufocar, e acordei estremunhado, compreendi que alguém me amordaçara. Estava um peso a esmagar-me, e eu sem as cuecas, a besta prendia-me os movimentos com um dos braços, com a mão livre enchia-me de cuspo o rabo. E rasgava-me, e eu não gritava porque não havia espaço, e rasgava-me, e voltava a rasgar-me, e eu ouvi a voz do louro, e era como se falasse por um funil na minha orelha, a bichanar isto o filho da grandessíssima puta, "Vá lá, meu, até que enfim, não estrebuches, meu, que eu tenho cuidadinho, eu tenho muito cuidadinho, meu, não estrebuches".

E eu só chorava, encharcado de sangue, ou do que quer que fosse, e aparecia-me a minha mãe, a tiritar de frio, enrolada na colcha com os dois tigres, a lutar na floresta, e no meio de um incêndio que reduzia tudo a cinzas. E a seguir ao louro enrabou-me o velho, e eu consciente, e o porcalhão vomitava estas palavras, "Ai, que menino de ouro, ai, que lindo, ai, que saudades eu tinha de uma coisinha assim!" E foram-se aproximando excepto um, e já não existia ninguém, nem a dor nem a camarata nem o Mundo. O firmamento abria-se 
à minha volta, eu voava, limpo como o gelo, apontava em todas as direcções para que as luzes se acendessem, e as luzes obedeciam-me como se interpretasse o papel de Deus.

O mulato foi o último e eu tornava a ser um pedaço de carne suja. E o badalhoco não parava nas minhas costas, e a parede ofuscava-se diante de mim com o recorte do Leonardo DiCaprio e da Kate Winslet, a apanhar a fresca na popa do Titanic. "Ele é igual ao Leonardo DiCaprio", jurava a alemã, e a irmã do meu amigo, muito simpática, a escovar-me assim, "Leonardo, isto", "Leonardo, aquilo", eu a pentear-me na casa-de-banho de um apartamento com uma decoração espetacular, e o meu amigo que me facilitava deste modo, "Não te retraias, ó pá, o dinheiro é para gastar, não é por isso que hás-de ter problemas." O mulato estremeceu, a gemer, e acalmou-se, mas continuou assapado sobre mim, e foi buscar uma toalha, e os meus olhos ardiam-me como se estivesse cego, e vira-se o monte de merda, atira com isto, "Agora, sim senhor, agora é que viste as estrelas, meu anjinho". E ele e os outros quatro botaram-se a rir aos soluços (CLÁUDIO, p. 177-179).

A leitura nos expõe a um desconforto físico semelhante ao sofrido por Jorge. Contribuem para isso as imagens que o texto constrói desde o início da cena: na cela onde ela se passa, a cama é do tipo beliche (em que, naturalmente, um indivíduo deita-se sobre o outro), há o sonho com um foguete totalmente cerrado, a personagem sente a compressão do pênis do estuprador, o sufocamento e, finalmente, apercebe-se da mordaça.

Logo, a descrição dos movimentos brutos dos agressores ata-nos à cena, num mórbido prazer causado pelo texto (pois, conforme Barthes, "o prazer do texto é esse momento em que meu corpo vai seguir suas próprias ideias - pois meu corpo não tem as mesmas ideias que eu” [BARTHES, 2006, p. 24]), com uma aceleração na velocidade da narração que apenas diminui quando, referindo-se à cena do filme Titanic, em que Leonardo DiCaprio e Kate Winslet encontram-se "a apanhar a fresca na popa" (CLÁUDIO, 2000, p. 178), o ritmo da violação causa enjoo à personagem. O movimento que embala os corpos enlaçados não é mais o do mar, mas o de um dos estupradores, que, engatado a este desgraçado Leonardo, levo-o a ver outras estrelas que não as do céu, ou as que costumava ver quando drogado, ou ainda as de Hollywood, que enfeitavam a parede de sua cela. A estrela que é Jorge, outrora elevada, é, agora, um corpo que cai, desfalecido, rasgado, banhado de sangue contaminado e desprovido de dignidade.

Esse sexo desautorizado remete a Georges Bataille quando afirma que: "a crueldade é uma das formas da violência organizada. Não é forçosamente erótica, mas pode derivar para outras formas de violência que a transgressão organiza. Como a crueldade, o erotismo é meditado" (BATAILLE, 2013, p. 103). A violência praticada contra Jorge fora premeditada por seus violadores, que erotizaram a sua imagem e desejaram-na, transgredindo regras sociais e de respeito ao espaço e ao corpo do outro. Se, para 
Jorge, o estupro foi um gesto de crueldade, para aqueles, foi a concretização de um desejo transgressor e, por isso, erótico. Na meditação desse gesto, enquanto Jorge se queixava por estar "farto desta seca" (CLÁUDIO, 2000, p. 166), referindo-se à falta dos comprimidos que lhe garantiam "o reacesso à liberdade" (CLÁUDIO, 2000, p. 167), seus companheiros de cela davam constantes mostras de um desejo de aproximação sexual que culminou com o estupro.

Por fim, a impossibilidade de reprodução oriunda desse ato criminoso engendra na vítima a doença com a qual, além do trauma, também terá de aprender a conviver, numa sucessão de aprisionamentos que flagelam o seu corpo e a sua existência: as drogas, a cadeia, o trauma, a doença, o abandono da família. Contudo, é ainda Bataille quem nos recorda de que "o pouco tempo que nos separa do vazio tem a consistência de um sonho" (BATAILLE apud DIDI-HUBERMAN, 2011, p. 139); nesse breve intervalo, ou seja, nessa brecha existente entre o pressentimento e a dor, Jorge decola em seu foguete para o espaço, aonde voa limpo e claro como o gelo do cadáver que ele quase é.

Tanto o conteúdo quanto a forma da cena da violação sugerem o apagamento do real. A referência ao passado e a símbolos afetivos já inacessíveis, como o cobertor de tigres da casa materna, que se perdeu em um incêndio, parece uma tática de desvio da crua realidade narrada. Do mesmo modo, a estratégia de descrever a cena do estupro utilizando a técnica do plano fechado ${ }^{3}$ demonstra que literatura, ao apropriar-se de um protocolo exterior, neste caso, o da linguagem cinematográfica, ocupa um lugar que não é o seu, relativizando qualquer possibilidade de certeza, seja ela temporal, no plano da narrativa, ou concernente à forma e ao conteúdo do narrado. Assim como as dores física e psicológica, produtos do trauma, podem ser relativizadas através do exercício criativo empreendido por Jorge, conforme discutiremos adiante, os dados do real também podem ser postos em discussão. A verdade, então, torna-se passível de inversão, de invenção e, até mesmo, de subversão, visto que,

construindo seus textos como uma espécie de quebra-cabeça, solicitando dos leitores remontagens e descobertas, Mário Cláudio situa seu trabalho no quadro das produções contemporâneas explicitamente conscientes e evidenciadoras da constituição ilusória do objeto artístico, de sua composição como algo que claramente se assume como construção, assim se opondo a uma pretensão mimética, à ocultação de sua própria natureza ficcional (CALVÃO, 2008, p. 57) ${ }^{4}$.

A cena do estupro é cuidadosamente tecida de modo que o corpo de Jorge, rasgado por seus estupradores, revisita elementos constitutivos de sua vida pregressa à prisão, num jogo perturbador de recostura dessa personagem dilacerada, como se, ao se tornar objeto do desejo violento dos companheiros de prisão, necessitasse da narrativa para ser recomposta. Sobre o aprendizado causado por esse estado melancólico, Denílson Lopes 
diz-nos que "o espaço da melancolia é o teatro dos sobreviventes, da fragilidade temporal, da quase-morte, quase-catástrofe, das máscaras mutantes, cambiantes, da metafísica em crise" (LOPES, 1999, p. 90), e, sendo assim, “a melancolia é uma estratégia de aprendizado e sobrevivência do sujeito em meio à dispersão" (LOPES, 1999, p. 91).

É no sentido da dor como aprendizado que as personagens do romance veem, cada qual ao seu modo, o exercício da criatividade como o único meio para vencer a melancolia de seus corpos aprisionados. Assim, a escrita - a do romance que temos em mãos - surge, no depoimento final de Jorge, como atividade fundamental à continuidade da existência enlutada:

De longe a longe, sonho com orgias, muita malta nua, todos enganchados uns nos outros, uma pouca-vergonha do caralho. E acordo molhado, e não era com aquilo que eu desejava sonhar. Mas como estou por minha vontade na unidade-livre-de-droga tomo um duche, vou até à janela da sala, fico a admirar o céu estrelado, aos poucos e poucos perco o medo. Há um psicólogo baril, também gosta de astros, explica-me coisas, não se cansa de me aconselhar, "Deves falar o mais possível do teu caso, aprende a viver com ele". E é isso o que estou a tentar agora. Ele toca-me no ombro, e diz, "São as sete estrelas da Ursamaior, Dubhe, Merak, Phacd, Megrez, Alioth, Mirach e Alcaid, e se prolongares cinco vezes a distância das guardas, encontras a Estrela Polar". Eu ponho-me então a contá-las, uma a uma, mas dou-lhes nomes diferentes, Henrique, Gerardo, Sérgio, Cristiana, Rogério, Albino e Jorge. Entretenho-me assim. E àquela mais à frente, à mais brilhante, à que aponta o Norte, poderei chamar-lhe, sei lá bem!, poderei chamar-lhe o que vocês quiserem (CLÁUDIO, 2000, p. 180).

Portanto, o entretenimento é encarado como necessidade vital. O corpo abusado, tornado inanimado por seus agressores, tal qual um pedaço de carne, pode ser reconstituído pela escrita, que paulatinamente faz secar as suas feridas, na tentativa que a personagem faz de, renomeando as estrelas da constelação que observa, conviver com o trauma sofrido. Se a estrela Alcaid corresponde, enfim, à história daquele que descobrimos, ao final, ser o autor das histórias lidas, essa personagem coloca-se, de acordo com a versão árabe que explica a constelação da Ursa Maior, como o líder das filhas do esquife - ou carpideiras $-^{5}$, alcunha que parece se encaixar bem na função que lhe cabe no romance. Essa posição de liderança, que, de acordo com a explicação grega, mencionada anteriormente, posiciona-se no que seria o rabo da ursa, confere a Jorge um olhar privilegiado sobre as demais personagens, a quem é capaz de tocar com o condão da ficção, cumprindo a função criadora de um deus imperfeito - ou de um escritor.

O romance faz-nos refletir sobre a visão barroca do homem, que parece ser retomada, em determinados aspectos, na estética contemporânea ${ }^{6}$, de que Mário Cláudio é assumido representante 7 . De modo especial 
em Ursamaior, fatores como o apagamento de certezas, a menção à cultura midiática, bem como outros jogos, como o fingimento e o uso de máscaras, são piscadelas de sentido (ECO, 1994) que fazem ecoar a tensão entre o luto e o jogo, que Walter Benjamin detalha em sua obra sobre o Trauerspiel. Segundo Maria Theresa Abelha Alves,

é interessante a estratégia utilizada por Mário Cláudio para criar e desfazer a ilusão referencial no que tange à questão autoral: apresenta-se como retrato na capa do livro e na descrição de Cristiana [a travesti, uma das sete personagens de Ursamaior], mas atribui a redação do romance a Jorge, numa assunção consciente da máscara (ALVES, 2006, p. 308. Adendo nosso).

Inscrito nesse jogo de máscaras, o martírio de Jorge serve, perversamente, como "acesso à pátria alegórica" (BENJAMIN, 1984, p. 241), e essa visão barroca parece ser atualizada, no âmbito do romance, no corpo (de)cadente da personagem, que conhece diferentes círculos do inferno - a pobreza, as drogas, a cadeia, o estupro, enfim, o aprisionamento de seu corpo, que deseja livre, "como se interpretasse o papel de Deus" (CLÁUDIO, 2000, p. 178), mas que só é capaz de redimir através da ficção, pois, afinal, permanecerá aprisionado. Desloca-se, portanto, para o campo do questionamento a certeza de Mário Cláudio ter reconstituído, em Ursamaior, um crime de fato ocorrido e noticiado. Nas dobras possibilitadas pela ficção, a realidade passa a ser apenas um detalhe, fruto da criação de uma personagem capaz de alterar a compreensão tanto do enredo quanto da realidade que o inspirara.

Mário Cláudio, escritor atento à realidade e ao seu tempo, revela, com a escrita da trilogia em que está inserido Ursamaior, uma preocupação com a melancolia de nossos dias. Se é verdade que a arte imita a vida, nas obras desse artista é possível afirmar que a arte excede a vida, pois é nela que ele busca elementos para a construção de sua literatura, que, invariavelmente, tira-nos do lugar comum, fazendo-nos erguer barthesianamente a cabeça para refletir sobre o real. Em Ursamaior, as personagens cometem crimes e, por isso, são punidas, mas é na cadeia, instituição que tolhe seus corpos aprisionados, que o poder criativo toma as rédeas da história e a reconstitui, culminando, com a narrativa de Jorge, na reescrita da realidade, que se dá graças ao aparentemente simples gesto de falar sobre um problema, de modo a aprender a conviver com ele.

Na mitologia da constelação fictícia criada por Jorge há histórias de furto, loucura, violação, tráfico, assassinato e outros comportamentos desviantes, assim como na mitologia da Ursa Maior há o castigo oriundo da transgressão amorosa; a partir de ambas, prolongando-se a distância entre as guardas por cinco vezes, pode ser vista a estrela mais brilhante, aquela que aponta o norte. Mário Cláudio, ao tomar este conjunto de estrelas para criar aquele, o seu próprio, estende a metáfora das estrelas a variados níveis, da popularidade à dor. Todas as personagens de Ursamaior 
vivenciaram experiências dolorosas, mas é Jorge, estrela correspondente ao líder das filhas do esquife, quem leva a dor às últimas consequências. Seu corpo protagoniza uma queda vertiginosa, como uma estrela em chamas que nós, leitores, observamos cair. Em sua catábase, Jorge experimenta o martírio físico e psicológico e lança mão da escrita como forma de vencer o luto de sua existência. Entretanto, convoca-nos, nas últimas palavras do romance, a com ele chamar a estrela mais brilhante do nome que nós quisermos, e essa abertura da narrativa desestabiliza, mais uma vez, qualquer possibilidade de leitura segura. Mário Cláudio inscreve-se em seu próprio texto, também, como leitor, uma vez que delega à personagem de sua imaginação a autoria do romance que temos em mãos, e uma vez mais mostra-nos que não há certezas. Muito mais que um to be continued, essa brecha que se abre para nós, ao final do texto, é como um buraco negro de que só se conhecem as dúvidas e os questionamentos. Revisitamos a cosmovisão barroca da história e enxergamo-nos em nossa fraqueza, bichos da terra tão pequenos que somos, diante de uma abóbada celeste imensa e praticamente desconhecida. Suportamos melhor a vida quando nos surpreende a beleza dolorida das estrelas cadentes.

\section{REFERÊNCIAS BIBLIOGRÁFICAS}

ALVES, Maria Theresa Abelha. O óbolo de Caronte: Ursamaior de Mário Cláudio. In: DUARTE, Lélia Parreira (org). As máscaras de Perséfone: figurações da morte nas literaturas portuguesa e brasileira contemporâneas. Rio de Janeiro: Bruxedo; Belo Horizonte: PUC-MINAS, 2006. p. 271-310.

ÁVILA, Affonso. O lúdico e as projeções do mundo barroco. São Paulo: Perspectiva, 1980.

BATAILLE, Georges. O erotismo. Trad. Fernando Scheibe. Belo Horizonte: Autêntica, 2013.

BARTHES, Roland. O prazer do texto. Trad. Guinsburg. São Paulo: Perspectiva, 2006.

BENJAMIN, Walter. Origem do drama barroco alemão. Tradução, apresentação e notas de Sergio Paulo Rouanet. São Paulo: Brasiliense, 1984.

CALABRESE, Omar. A idade neobarroca. Trad. Carmen de Carvalho e Artur Morão. Lisboa: Edições 70, 1988.

CALVÃO, Dalva. Narrativas biográficas e outras artes: reflexões sobre escrita literária e criação estética na Trilogia da mão, de Mário Cláudio. Niterói: Editora da Universidade Federal Fluminense, 2008.

CLÁUDIO, Mário. Ursamaior. Lisboa: Dom Quixote, 2000.

COMPAGNON, Antoine. Literatura para quê? Trad. Laura Taddei Brandini. Belo Horizonte: Editora UFMG, 2009. 
COSTA, Mariana Caser da. "Desvendando as constelações, uma janela para a noite": aspectos de luto e jogo em Ursamaior, de Mário Cláudio. [Dissertação de Mestrado em Estudos de Literatura.] Instituto de Letras, Universidade Federal Fluminense, Niterói, 2012. 175 f.

DIDI-HUBERMAN, Georges. Sobrevivência dos vagalumes. Trad. Vera Casa Nova e Márcia Arbex. Belo Horizonte: Editora UFMG, 2011.

ECO, Umberto. Seis passeios pelos bosques da ficção. Trad. Hildegard Feist. São Paulo: Companhia das Letras, 1994.

LOPES, Denilson. Nós os mortos: melancolia e Neobarroco. Rio de Janeiro: Sette Letras, 1999.

NETO, Anastácio. Entrevista a Mário Cláudio (parte I). O vício da arte. 2006. Disponível em: <http://oviciodaarte.blogspot.com.br/2006/09/ entrevista-mrio-cludio-parte-i.html>. Acesso em: 2 fev. 2017.

PRIMEIRO FILME. O livro. 20--. Disponível em: http://www.primeirofilme.com.br/site/o-livro/enquadramentos-planos-e-angulos/. Acesso em: 5 fev. 2017.

SARDUY, Severo. Barroco. Trad. Maria de Lurdes Júdice e José Manuel de Vasconcelos. Lisboa: Vega, 1989.

URSA MAIOR. Disponível em: <http://explicatorium.com/constelacao/ursa-maior.html>. 20--. Acesso em: 29 jan. 2017.

Recebido para publicação em 01/03/2017

Aprovado em 15/04/2017

\section{NOTAS}

1 Doutoranda em Literatura Comparada pela Universidade Federal Fluminense - UFF, sob orientação do professor Luis Maffei; mestre em Estudos de Literatura na área de Literatura Portuguesa pela UFF (2012), tendo defendido a dissertação intitulada “'Desvendando as constelações, uma janela para a noite’: aspectos de luto e jogo em Ursamaior, de Mário Cláudio"; bolsista Capes. E-mail: caser.mariana@gmail.com.

2 Ver: COSTA, 2012, p. 28. Este parágrafo faz referência à análise proposta em minha dissertação de mestrado, defendida em 2012 e mencionada nas referências deste artigo. A propósito, as reflexões engendradas neste texto são desdobramentos daquele estudo, que teve por orientadora a professora Dalva Calvão.

3 "Plano fechado (close-up): a câmera está bem próxima do objeto, de modo que ele ocupa quase todo o cenário, sem deixar grandes espaços à sua volta. É um plano de INTIMIDADE e EXPRESSÃO" (PRIMEIRO FILME, 20--. Destaques do autor).

4 Sobre essa questão, ver, por exemplo, no conjunto da obra de Mário Cláudio, o romance Camilo Broca, em que o autor põe em xeque a figura consagrada de Camilo Castelo Branco, dando voz a uma suposta irmã do escritor que seria, ela sim, o grande gênio da família. Conforme mencionado nos parágrafos iniciais deste artigo, o caráter lúdico das obras marioclaudianas, que são, em geral, autoirônicas, autorreferenciais e metalinguísticas, favorece que a ficção rompa os limites de realidade, discutindo certezas, cânones e, enfim, conduzindo a uma importante reflexão acerca do papel da arte e do artista. 
5 Para os árabes, o desenho formado pelas estrelas da constelação de Ursa Maior era o de um caixão funerário seguido de carpideiras.

6 Conforme preconizam estudiosos como, por exemplo, Omar Calabrese (1988), Severo Sarduy (1989) e Afonso Ávila (1980).

7 "O estilo de um autor não é uma questão de opção, mas sim de natureza. Escrevemos aquilo que somos e não como gostaríamos de ser. Tendo-se uma estrutura de carácter excessiva, barroca, não se pode escrever de forma neoclássica, por exemplo. A maneira como se escreve, o estilo que se adopta, é reflexo da maneira com somos construídos por dentro, isso não se pode alterar com facilidade." (Conforme NETO, 2006). 